OPEN ACCESS

Edited by:

Guigen Li,

Texas Tech University, United States

Reviewed by:

Zhu Liang,

South China University of Technology,

China

Sarita Kumar,

University of Delhi, India

*Correspondence:

Dongli $\mathrm{Li}$

wyuchemldl@126.com

Weiqian David Hong davidhwq@liverpool.ac.uk

Specialty section: This article was submitted to

Organic Chemistry,

a section of the journal

Frontiers in Chemistry

Received: 12 March 2021 Accepted: 06 May 2021

Published: 24 May 2021

Citation:

Wu P, Tang X, Jian R, Li J, Lin M, Dai H, Wang $K$, Sheng Z, Chen B, XuX, Li C, Lin Z, Zhang Q, Zheng X, Zhang K, LiD

and Hong WD (2021) Chemical

Composition, Antimicrobial and Insecticidal Activities of Essential Oils of Discarded Perfume Lemon and Leaves (Citrus Limon (L.) Burm. F.) as Possible

Sources of Functional

Botanical Agents.

Front. Chem. 9:679116.

doi: 10.3389/fchem.2021.679116

\section{Chemical Composition, Antimicrobial and Insecticidal Activities of Essential Oils of Discarded Perfume Lemon and Leaves (Citrus Limon (L.) Burm. F.) as Possible Sources of Functional Botanical Agents}

Panpan Wu ${ }^{1,2}$, Xiaowen Tang ${ }^{1,2}$, Rongchao Jian ${ }^{1,2}$, Jiahao Li $^{1,2}$, Maoyu Lin ${ }^{1,2}$, Huachao Dai ${ }^{1,2}$, Kangpeng Wang ${ }^{1,2}$, Zhaojun Sheng ${ }^{1,2}$, Baizhong Chen ${ }^{3}$, Xuetao $\mathrm{Xu}^{1,2}$, Chen $\mathrm{Li}^{1,2}$, Zhongze Lin ${ }^{1,2}$, Qingmin Zhang ${ }^{1,2}, X^{1}$ Zheng ${ }^{1,2}$, Kun Zhang ${ }^{1,2}$, Dongli $\mathrm{Li}^{1,2 *}$ and Weiqian David Hong ${ }^{1,2,4 *}$

${ }^{1}$ School of Biotechnology and Health Sciences, Wuyi University, Jiangmen, China, ${ }^{2}$ International Healthcare Innovation Institute (Jiangmen), Jiangmen, China, ${ }^{3}$ Guangdong Xinbaotang Biotechnology Co. Ltd., Jiangmen, China, ${ }^{4}$ Department of Chemistry, University of Liverpool, Liverpool, United Kingdom

Two essential oils were isolated from discarded perfume lemon and leaves (Citrus limon (L.) Burm. F.) by hydro-distillation with good yield $(0.044 \%$ for perfume lemon and $0.338 \%$ for leaves). Their biological activities were evaluated against five selected bacterial strains and Aedes albopictus (Ae. albopictus, Diptera: Culicidae). Chemical composition indicated that both essential oils were rich in essential phytochemicals including hydrocarbons, monoterpenes and sesquiterpene. These constituents revealed some variability among the oils displaying interesting chemotypes $(R)-(+)$-limonene (12.29-49.63\%), citronellal (5.37-78.70\%) and citronellol (2.98-7.18\%). The biological assessments proved that the two essential oils had similar effect against bacterial (inhibition zones diameter ranging from $7.27 \pm 0.06$ to $10.37 \pm 0.15 \mathrm{~mm}$; MICs and MBCs ranging from 1.6 to $6.4 \mathrm{mg} / \mathrm{mL}$ ); against Ae. albopictus larvae ( $\mathrm{LC}_{50}$ ranging from 384.81 to $\left.395.09 \mathrm{ppm}\right)$ and adult mosquito $\left(\mathrm{LD}_{50}\right.$ ranging from 133.059 to $\left.218.962 \mu \mathrm{g} / \mathrm{cm}^{2}\right)$; the activity of the two chemotypes $((R)$ (+)-limonene and citronellal): larvae ( $\mathrm{LC}_{50}$ ranging from 267.08 to 295.28 ppm), which were all presented in dose-dependent manners. Through this work, we have showcased that recycling and reusing of agriculture by-products, such as discarded perfume lemon and leaves can produce eco-friendly alternatives in bacterial disinfectants and mosquito control product.

Keywords: chemical composition, antimicrobial, insecticidal, essential oil, perfume lemon, leaves

\section{INTRODUCTION}

Many mosquito-borne tropical and subtropical diseases, such as malaria, yellow fever, filariasis, dengue, and viral encephalitis (Rouis et al., 2013; Duguma, et al., 2020; Wilson, et al., 2020) contribute to a larger proportion of public health problems and a major economic burden within disease-endemic countries (Bhatt et al., 2013; Pavela, 2015). Left unchecked, insecticide resistance 


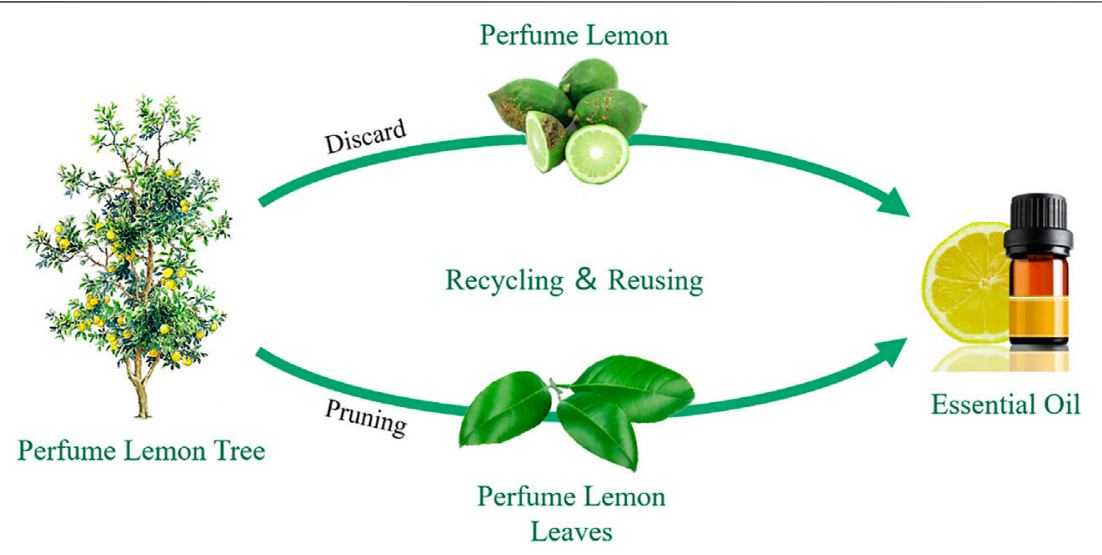

FIGURE 1 | Recycling and reusing of the discarded perfume lemon and leaves.

could lead to a substantial increase in mosquito-borne diseases incidence and mortality (Weill et al., 2003; Liu, 2015; Chang et al., 2017). Herein, urgent action is required to prevent the further development of resistance (Ranson and Lissenden, 2016) and to maintain the effectiveness of existing vector control interventions (Shaw and Catteruccia, 2019; Wilson et al., 2020). In addition to that, it would provide significant added value if the newly developed products can be used to control bacterial infection e.g. caused by scratching of the irritated skin or other inflammation reactions after mosquito bites (Ivory et al., 2015; Derua et al., 2019).

More and more studies have been carried out and suggested that plant extractions are effective against mosquitoes at various stages of development (Bakkali et al., 2008; Gross et al., 2017). Citrus fruits (family Rutaceae) are among the most widely produced fruits all over the world (Zhang et al., 2017). The perfume lemon is a major genus of the family Citrus limon, which has been widely cultured in southern China. As shown in Figure 1, the discarded perfume lemon used in this study primarily resulted from commercial demand of a fixed range of fruit size, especially in the process of fruit tea preparation. Perfume lemon leaves came mainly from the pruning of perfume lemon trees, which were often discarded as a waste product, with some adverse effects on the local environment and ecology. Thus, reusing of discarded perfume lemon and leaves is not only beneficial to the comprehensive utilization of natural resources, but also can turn waste into treasure and increase the added value of the agricultural process.

The two essential oils of discarded perfume lemon and leaves were obtained by hydro-distillation; their chemical compositions were determined by gas chromatography-mass spectrometry (GC-MS) analyses (Peng et al., 2014). The aim of this study was to investigate the antibacterial and larvicidal potentials of the perfume lemon and leaf essential oils against the selected bacteria, the larval and adult Aedes albopictus (Ae. albopictus, Diptera: Culicidae). Comparison of active components and their active ingredients were also discussed. The reduced usage of synthetic insecticides by replacement of plant origin product is being considered as safe alternatives for environment and human health (Pavela, 2015; Pavela and Benelli, 2016).

\section{MATERIALS AND METHODS}

\section{Plant Material and Chemicals}

Discarded perfume lemon and leaves (Citrus limon (L.) Burm. F. Appraised by Professor Junxia Zheng of Guangdong University of Technology) were obtained from the local farm (Xinghong farm, Enping, Jiangmen, Gaungdong, China). Mueller-Hinton agar (MHA) and Mueller-Hinton broth (MHB) were purchased from Guangdong Huankai Microbial Technology Co., Ltd. (Guangdong, China), custom alkanes solution of $\mathrm{C}_{8}-\mathrm{C}_{40}$ n-alkanes standard (Reagent Brand: o2si) was bought from ANPEL Laboratory Technologies (Shanghai, China). Deltamethrin was purchased as analytical reagent from J\&K Scientific (Beijing, China). (R)-(+)-Limonene and citronellal were purchased from Aladdin chemical company (Shanghai, China). Other reagents were obtained as analytical reagents from Tansoole (Shanghai, China).

\section{Extraction and Chemical Analysis of Discarded Fresh Perfume Lemon and Leaves Essential Oils}

The discarded fresh perfume lemon and leaves were suspended in distilled water with a solid-liquid ratio of 1: $4(\mathrm{~W} / \mathrm{V})$, and the aliquot was placed in a $2.5 \mathrm{~L}$ round-bottomed sample flask which was then hydro-distilled for $1.5 \mathrm{~h}$ after the water and sample mixture started to boil. The essential oils were collected by oilwater separator, which then dried over anhydrous $\mathrm{MgSO}_{4}$ and filtered through a microporous membrane.

Chemical components of the two essential oils were analyzed on a Thermo Scientific TRACE 1300 Gas Chromatograph coupled to an ISQ Qd Mass Spectrometer and equipped with a TG-5 MS capillary column $(30 \mathrm{~m} \times 0.25 \mathrm{~mm}$ i.d., $0.25 \mu \mathrm{m}$ film thickness, Thermo Scientific). Helium was used as the carrier gas with a flow rate of $1 \mathrm{ml} / \mathrm{min}$. The oven temperature was programmed for $2 \mathrm{~min}$ at $60^{\circ} \mathrm{C}$, then raised to $160^{\circ} \mathrm{C}$ at $5^{\circ} \mathrm{C} /$ min and held for $2 \mathrm{~min}$, then increased to $260^{\circ} \mathrm{C}$ at $20^{\circ} \mathrm{C} / \mathrm{min}$ and maintained for $20 \mathrm{~min}$. The temperature of injector and MS 
transfer line was set to $280^{\circ} \mathrm{C}$; temperature of ion source was set to $320^{\circ} \mathrm{C}$. Mass spectra were recorded in the electron impact ionization (EI) at $70 \mathrm{eV}$. The scan range was from 35 to $450 \mathrm{~m} / z$. Identification of the components of the two essential oils was based on the search results of NIST mass spectral library, together with comparisons of commercially available standards and Kovats indices (KI). The KI was determined relative to the retention times of a $\mathrm{C}_{8}-\mathrm{C}_{40} \mathrm{n}$-alkanes standard, and calculated as Eq. 1. Then the calculated KI was compared with the KI of NIST Chemistry WebBook.

$$
K I=100 n+\frac{100\left(t_{x}-t_{n}\right)}{t_{n+1}-t_{n}} .
$$

In Eq. $1 t_{x}$ means the retention time of analyzed component $(\min ) ; t_{n}$ means the retention time of $n$-alkane in which carbon number is $n ; t_{n+1}$ means the retention time of $n$-alkane in which carbon number is $n+1$; and $t_{n}<t_{x}<t_{n+1}$.

\section{Microorganisms and Culture Media}

The bacterial strains of two Staphylococcus aureus (ATCC 6538 and ATCC 29213), Staphylococcus epidermidis (ATCC 12228), Salmonella typhimurium (CMCC 50115) and Escherichia coli (CMCC 44102) were obtained from Guangdong Culture Collection Center (Guangdong, People's Republic of China). All the five strains were cultured in Mueller-Hinton agar (MHA) and Mueller-Hinton broth (MHB).

\section{Agar Disk Diffusion Assay of the Two Essential Oils}

The antimicrobial of essential oils were determined according to the standard agar disk diffusion method with a slight modification (Luangtongkum et al., 2007; Gaudreau et al., 2008; Benamrouche et al., 2014; Wu et al., 2018; Wu et al., 2021). A 0.5 McFarland $\left(1 \times 10^{7}\right.$ to $\left.1 \times 10^{8} \mathrm{CFU} / \mathrm{mL}\right)$ concentration of the bacterial suspension was uniformly inoculated onto MHA solidified in $120 \mathrm{~mm}$ Petri dishes. Once the dishes were prepared, $6 \mathrm{~mm}$-diameter discs of filter paper containing $5 \mu \mathrm{L}$ of the examined essential oil solutions, which had been diluted with dimethyl sulfoxide (essential oil: DMSO 1:9 v/ v), were pressed gently against the surface of the agar. Discs containing gatifloxacin ( $1 \mathrm{nmol})$ was used as positive control, while DMSO was used as the negative control. The dishes were incubated in a constant temperature incubator at $37^{\circ} \mathrm{C}$ for $24 \mathrm{~h}$. The inhibition zone diameter was measured by a vernier caliper. All the experiments were performed in triplicate (Wu et al., 2021).

\section{Broth Microdilution Assay of the Two Essential Oils}

The minimum inhibitory concentration (MIC) and the minimum bactericidal concentration (MBC) were determined by a microdilution method in 96-well plates according to Clinical and Laboratory Standards Institute (CLSI), with a slight modification (Sader et al., 2006; Meng et al., 2016; Wu et al., 2018; Wu et al., 2021). A series of diluted essential oils were prepared with DMSO as the solvent by two-fold serial dilution starting from a stock solution of $512 \mathrm{mg} / \mathrm{mL}$. The final concentrations of the test essential oils were obtained in a range between $1 \mathrm{mg} / \mathrm{mL}$ and $512 \mathrm{mg} / \mathrm{mL}$. Each well received $5 \mu \mathrm{L}$ of a specific concentration of the essential oils and $195 \mu \mathrm{L}$ of MHB inoculated with the test microorganism $\left(1.5 \times 10^{5} \mathrm{CFU} / \mathrm{mL}\right)$; the final concentrations of the examined essential oils were reached. Gatifloxacin was used as positive control and DMSO was used as negative control (Wu et al., 2021). The microplates were incubated in a bacteriological oven for $24 \mathrm{~h}$ at $37^{\circ} \mathrm{C}$, and the susceptibility results of tested samples were monitored by measuring the absorbance at $600 \mathrm{~nm}$ using a Multimodel Plate Reader (Infinite 200). The lowest concentration without visible growth was defined as the MIC (Wu et al., 2021).

The minimum bactericidal concentrations (MBCs) were determined based on the MIC results (Jabrane et al., 2010; Chouaib et al., 2015; Wu et al., 2018; Wu et al., 2021): serial sub-cultivation of a $5 \mu \mathrm{L}$ aliquots near the MIC with $195 \mu \mathrm{L}$ fresh MHB were uniformly inoculated onto MHA solidified in $90 \mathrm{~mm}$ Petri dishes; incubation for $24 \mathrm{~h}$ at $37^{\circ} \mathrm{C}$. The lowest concentration of antimicrobial agent that killed at least $99.9 \%$ of the starting inoculum was defined as the MBC endpoint, which was determined as the lowest concentration with no visible growth of bacterial colony on the Petri dishes ( $\mathrm{Wu}$ et al., 2021). All experiments were conducted in triplicate. The final concentration of DMSO in the 96-well plate had no effect on bacterial growth.

\section{Killing Kinetic Studies of the Two Essential Oils}

The killing kinetic studies of the two essential oils on tested bacteria strains (Theophel et al., 2014; Phee et al., 2015; Meng et al., 2016; Wu et al., 2018), including two strains of Staphylococcus aureus (ATCC 6538 and ATCC 29213), Staphylococcus epidermidis (ATCC 12228), Salmonella typhimurium (CMCC 50115) and Escherichia coli (CMCC 44102), were performed in 96-well plates, respectively. Four different concentrations (negative, $0.5 \times$ MIC, $1 \times$ MIC, $2 \times \mathrm{MIC}$ ) of each essential oil were studied. The microplates were incubated for $24 \mathrm{~h}$ at $37^{\circ} \mathrm{C}$, and the growth of bacteria was monitored by measuring the absorbance at $600 \mathrm{~nm}$ using a Multimodel Plate Reader (Infinite 200) every $1 \mathrm{~h}$ (Wu et al., 2021).

\section{Mosquitoes}

A local strain of Ae. albopictus larvae were collected at Huangpu District, Guangzhou, Guangdong Province, China, and had been maintained consecutively since 2013 in the laboratory. The species were reared at 14:10 light/dark photoperiod, $70 \pm 5 \%$ relative humidity at $26 \pm 2^{\circ} \mathrm{C}$, in the laboratory of International Healthcare Innovation Institute (Jiangmen), Jiangmen, China. Larvae were fed daily with fish food, and adults were fed with $5 \%$ glucose solution. The fourth instar larvae and two to five-days-old female mosquitoes were used in this bioassay. 


\section{Larvicidal Assay}

The larvicidal activity was tested by immersion method in a $24-$ well plate according to the standard procedures recommended by the World Health Organization, with slight modifications (WHO, 2005; Seo et al., 2015; dos Santos Moreira et al., 2018). Firstly, the two essential oils, $(R)-(+)$-limonene and citronellal are diluted in acetone to prepare an acetone solution with a series of concentration of $0-800 \mathrm{ppm}$. Then, five larvae were transferred into the series testing solution each well for testing with no feeding during the screening. Mortality was determined after $24 \mathrm{~h}$ of exposure. Three replicates were carried out for each sample. The mortalities of each essential oil sample ranging from 0 to $100 \%$ were obtained. At least 10 concentrations were selected to determine the $\mathrm{LC}_{20}, \mathrm{LC}_{50}$, and $\mathrm{LC}_{80}$. Three replicates were carried out for every sample at every concentration. Deltamethrin was used as positive control while blank reference was used as negative control.

Adjusted mortality is calculated by Eq. 2:

Adjusted mortality $(\%)=\frac{\text { mortality of testing group }- \text { mortality of blank group }}{1-\text { mortality of blank group }} \times 100$.

\section{Adulticidal Bioassays}

Adulticidal bioassays were assayed using Tarsal contact assay according to the reported method with slight modification (Chansang et al., 2018; Lees et al., 2019). Firstly, a graduated series of concentrations $\left(0 \sim 200 \mu \mathrm{g} / \mathrm{m}^{2}\right)$ of deltamethrin, essential oils and the two chemotypes $((R)-(+)$-limonene and citronellal) sample solution in acetone were prepared. Then, the sample solution was covered on the surface of $60 \mathrm{~mm}$ glass Petri dishes evenly. Bioassays were conducted immediately after the $4 \mathrm{~h}$ drying period, at $26 \pm 2^{\circ} \mathrm{C}$ and ambient humidity. Ten female adults (2-5 days old) were exposed in each Petri dish. A $25 \mathrm{~mL}$ plastic deli pot with a hole melted through the base was fixed onto each Petri dish with Parafilm. Mosquitoes were introduced through the hole and, after exposing them to the treated surface for $1 \mathrm{~h}$, they were aspirated out and transferred to holding cups. Then mosquitoes were put in an incubator with constant temperature $\left(26 \pm 2^{\circ} \mathrm{C}\right)$ and humidity $(70 \pm 5 \%)$, and fed with sugar solution. Mortality was determined after $24 \mathrm{~h}$ of incubation. Three duplicate trials were carried for every concentration. Blank reference was treated as negative control while deltamethrin was used as positive control. The adjusted mortality was calculated by the formula mentioned in Larvicidal Assay (Eq. 2). The concentration is expressed as $\mu \mathrm{g}$ of deltamethrin per $\mathrm{m}^{2}$ of surface of culture dishes. Regression analysis of adjusted mortalities vs. the concentrations of each examined sample to give toxicity regression equations.

\section{RESULTS AND DISCUSSION Chemical Composition of the Two Essential Oils}

The essential oils extracted from discarded perfume lemon and leaves were prepared by traditional hydro-distillation with yield of $0.044 \%(w / w)$ for perfume lemon and $0.338 \%(w / w)$ for leaves.
GC-MS was employed to identify the constituents and their relative content in the essential oils by the method of Kovats indices (Retention indices), and the results were as presented in Table 1 and Figure 2. The chemical structures of major components in the two essential oils were as presented in Figure 3.

As indicated in Table 1 and Figure 2, 26 components were identified from the two essential oils, representing almost $100 \%$ of the total amount. The predominant component of the fresh perfume lemon essential oil was $(R)-(+)$-limonene, representing $49.63 \%$, only $12.24 \%$ of this component was detected in the fresh leaves. In comparison, it was found that the component of citronellal in the essential oil extracted from leaves was the highest, reaching $78.35 \%$. Other types of five alcohols and two aldehydes were detected in fresh perfume lemon essential oil, whilst $7.18 \%$ of citronellol was also found in leaves. An ester, citronellyl acetate was identified in the essential oil extracted from the leaf, but not from the fruit.

Apart from the predominant component, the lemon essential oil is composed of $d$-limonene, $\gamma$-terpinene and $\beta$-pinene, followed by four other monoterpene hydrocarbons (myrcene, sabinene, $\alpha$-pinene and $p$-cimene) and other compounds in five different classes (sesquiterpene hydrocarbons, carbonyl compounds, alcohols, esters and oxides). In comparison to other previously reported analysis of essential oils from similar sources, most of the identified components are the same, but the composition of these components is different. For example, the percentages of citronellol and citronellal determined from the essential oils in this study are higher than in previous report and some of the less volatile components are also slightly different (Ciriminna et al., 2017; Yazgan et al., 2019).

\section{Antibacterial Activity of the Two Essential Oils}

The antibacterial activity of the two essential oils was assayed against five microorganisms, including two Gram-negative bacteria strains and three Gram-positive bacteria strains. All the bacterial strains were cultured in Muller Hinton agar at $37^{\circ} \mathrm{C}$ overnight (Wu et al., 2021).

\section{Agar Disk Diffusion Assay of the Two Essential Oils}

The antimicrobial activity of the two essential oils against the five different microorganisms are summarized in Table 2. $5 \mu \mathrm{L}$ of pure essential oil or $512 \mathrm{mg} / \mathrm{mL}$ acetone solution of essential oil on the filter paper was tested in this agar disk diffusion assay. The sizes of the inhibition zone diameters assay suggest that the antibacterial activity of the two essential oils against Grampositive strains is higher than that against Gram-negative strains. The results also indicate that the perfume lemon essential oil was more potent than the leaves essential oil, in which the inhibition zones diameter were in the range from $7.27 \pm$ 0.06 to $10.37 \pm 0.15 \mathrm{~mm}$ of three tested Gram-positive Staphylococcus strains. However, both essential oils displayed no inhibitory activity against the two selected Gram-negative bacteria strains. Interesting, while testing the one of main components of the essential oils, $(R)-(+)$-limonene, showed 
TABLE 1 | Chemical compositions of fresh perfume lemon and leaves essential oils.

\begin{tabular}{|c|c|c|c|c|c|c|c|}
\hline \multirow[t]{2}{*}{ No } & \multicolumn{2}{|l|}{ Component $^{a}$} & \multirow[t]{2}{*}{$\mathrm{RT}^{\mathrm{b}}$ (min) } & \multirow[t]{2}{*}{$\mathbf{K I}^{\mathrm{c}}$} & \multirow[t]{2}{*}{ KI lit ${ }^{d}$} & \multirow{2}{*}{$\begin{array}{l}\text { Perfume lemon } \\
\text { (\%) }\end{array}$} & \multirow{2}{*}{$\begin{array}{l}\text { Perfume lemon } \\
\text { leaves }(\%)\end{array}$} \\
\hline & Name & CAS no & & & & & \\
\hline 1 & $\beta$-myrcene & $123-35-3$ & 7.546 & 990 & 990 & 1.49 & 0.56 \\
\hline 2 & octanal & 124-13-0 & 7.871 & 1,002 & 1,002 & 0.49 & ND \\
\hline 3 & $(\mathrm{R})-(+)$-limonene & $5,989-27-5$ & 8.626 & 1,030 & 1,028 & 46.04 & 11.38 \\
\hline 4 & ocimene mixture of isomers & $3,338-55-4$ & 9.102 & 1,047 & 1,047 & 0.19 & 0.47 \\
\hline 5 & 3,8-p-menthadiene & $586-67-4$ & 9.746 & 1,070 & 1,071 & 0.34 & ND \\
\hline 6 & alpha, p-dimethylstyrene & $1,195-32-0$ & 10.288 & 1,090 & 1,090 & 0.20 & ND \\
\hline 7 & linalool & $78-70-6$ & 10.562 & 1,099 & 1,098 & 2.29 & 0.75 \\
\hline 8 & nonanal & $124-19-6$ & 10.678 & 1,104 & 1,104 & 0.44 & 0.28 \\
\hline 9 & $(-)$-isopulegol & 89-79-2 & 11.92 & 1,148 & 1,150 & 3.87 & ND \\
\hline 10 & citronellal & $106-23-0$ & 12.067 & 1,153 & 1,153 & 4.71 & 75.34 \\
\hline 11 & $\begin{array}{l}\text { (1R,2R,5S)-5-methyl-2-(prop-1- } \\
\text { en-2-yl) cyclohexanol }\end{array}$ & - & 12.229 & 1,159 & - & 2.39 & ND \\
\hline 12 & $\begin{array}{l}\text { 2-(4-methyl-2,4-cyclohexadienyl)- } \\
\text { 2-propanol }\end{array}$ & 1,686-20-0 & 12.523 & 1,169 & 1,168 & 1.40 & ND \\
\hline 13 & terpinen-4-ol & $562-74-3$ & 12.898 & 1,182 & 1,181 & 0.71 & ND \\
\hline 14 & 2-(4-methylphenyl) propan-2-ol & $1,197-01-9$ & 13.03 & 1,187 & 1,187 & 0.43 & ND \\
\hline 15 & a-terpineol & $98-55-5$ & 13.197 & 1,193 & 1,189 & 4.04 & ND \\
\hline 16 & decanal & $112-31-2$ & 13.541 & 1,205 & 1,205 & 0.37 & 0.79 \\
\hline 17 & $\begin{array}{l}\text { (Z)-carveol,2-methyl-5-(1-methy } \\
\text { lethenyl)-2-cyclohexen-1-ol, } \\
\text { cis-mentha-1,8-dien-6-ol }\end{array}$ & $1,197-06-4$ & 13.658 & 1,209 & 1,210 & 0.19 & ND \\
\hline 18 & citronellol & $106-22-9$ & 14.18 & 1,229 & 1,228 & 2.70 & 6.68 \\
\hline 19 & neral & $106-26-3$ & 14.56 & 1,242 & 1,241 & 10.57 & 0.51 \\
\hline 20 & nerol & $106-25-2$ & 14.92 & 1,256 & 1,259 & 0.59 & ND \\
\hline 21 & geranial & $141-27-5$ & 15.371 & 1,272 & 1,271 & 15.79 & 0.50 \\
\hline 22 & citronellyl acetate & $150-84-5$ & 17.545 & 1,353 & 1,353 & 0.07 & 1.70 \\
\hline 23 & neryl acetate & $141-12-8$ & 18.336 & 1,383 & 1,381 & 0.13 & 0.51 \\
\hline 24 & $\beta$-caryophyllene & $87-44-5$ & 19.415 & 1,426 & 1,425 & ND & 0.52 \\
\hline 25 & $\begin{array}{l}\text { 2,6-dimethyl-6-(4-methyl-3-pent } \\
\text { enyl)bicyclo[3.1.1]hept-2-ene }\end{array}$ & $17,699-05-7$ & 19.75 & 1,439 & 1,440 & 0.22 & ND \\
\hline 26 & $\beta$-bisabolene & $495-61-4$ & 21.538 & 1,510 & 1,510 & 0.32 & ND \\
\hline
\end{tabular}

${ }^{a}$ Components are listed in the order of KI values. Only major components (content $>0.1 \%$ ) are listed in the table.

${ }^{b}$ Kovats indices ( $\mathrm{min}$ ).

${ }^{c}$ Linear Kovats indices homologous series of $\mathrm{C}_{8}-C_{30}$ alkanes performed on a TG-5MS column.

${ }^{d}$ Linear Kovats indices were taken from https://webbook.nist.gov/chemistry/.

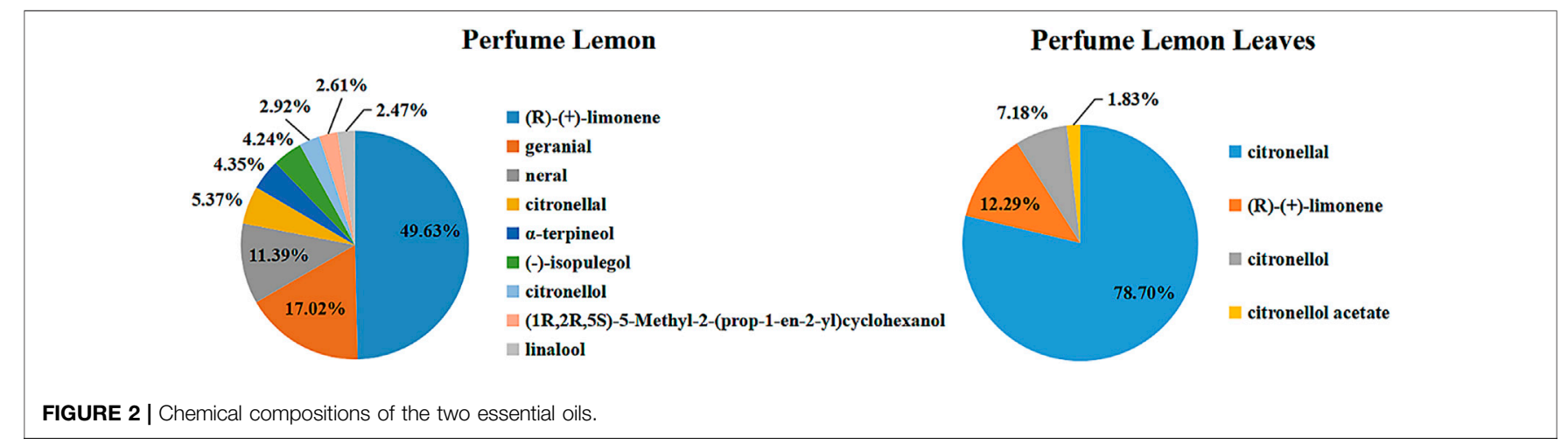

similar activity against Gram-positive bacteria, this compound displayed higher antibacterial activity against Gram-negative bacteria than the essential oils.

\section{Broth Microdilution Assay of the Two Essential Oils}

Using the micro-dilution method, the essential oils extracted from discarded perfume lemon and leaves were tested in the MICs and MBCs assays and the results are presented in
Table 3. The similar MIC and MBC values suggested that the two essential oils had inhibitory activity through a bactericidal effect against three Gram-positive strains of Staphylococcus, with both MICs and MBCs ranging from 1.6 to $6.4 \mathrm{mg} / \mathrm{mL}$. However, in contrast to the results from the agar disk diffusion assay, the results from the broth assays indicated that the essential oil extracted from the fruit was also active against the two tested strains of Gram-negative 


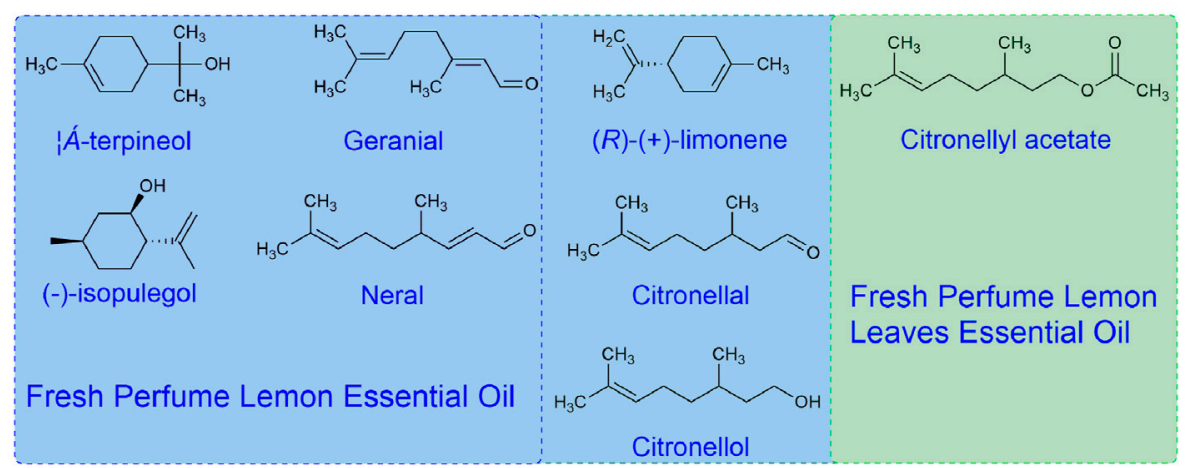

FIGURE 3 | Chemical structures of major components in the two essential oils.

TABLE 2 | Biological evaluation of the two essential oils expressed in the inhibition zone ( $\mathrm{mm})$.

Sample code

Bacterium and inhibition zone $(\mathrm{mm})^{\mathrm{a}}$

\begin{tabular}{ccc}
\hline \multicolumn{3}{c}{ Gram-positive bacteria strains } \\
\hline Staphylococcus aureus & Staphylococcus aureus & Staphylococcus \\
(ATCC & (ATCC & epidermidis (ATCC \\
6538 ) & 29213 ) & 12228 )
\end{tabular}

\begin{tabular}{cc}
\multicolumn{2}{c}{ Gram-negative bacteria strains } \\
\hline Salmonella & Escherichia \\
typhimurium (CMCC & coli (CMCC \\
$50115)$ & $44102)$
\end{tabular}

Perfume lemon essential oil

$9.87 \pm 1.15$
$10.37 \pm 0.67$
$8.97 \pm 1.10$
$8.20 \pm 0.26$
$N{ }^{\#}$
$6.77 \pm 0.23$
$N D$
$N D$
$19.12 \pm 0.73$

$8.57 \pm 0.61$

$9.10 \pm 0.78$

$<6^{\mathrm{b}}$

$<6$

Perfume lemon essential oil

$(100 \%)^{\mathrm{c}}$

Perfume lemon leaves

essential oil $(2.56 \mathrm{mg})$

Perfume lemon leaves

essential oil $(100 \%)^{\mathrm{C}}$

$(R)-(+)$-limonene $(2.56 \mathrm{mg})$

$(R)-(+)$-limonene $(100 \%)^{c}$

Citronellal $(2.56 \mathrm{mg})$

Citronellal $(100 \%)^{\mathrm{C}}$

Gatifloxacin $^{\text {d }}$

$19.12 \pm 0.73$

$10.20 \pm 0.52$

$10.37 \pm 0.15$

$7.27 \pm 0.06$

$7.53 \pm 0.61$

$7.37 \pm 0.12$

$8.23 \pm 0.31$

ND

$6.70 \pm 0.50$

ND

$\mathrm{ND}$

$17.13 \pm 0.64$

\section{ND}

$7.13 \pm 0.25$

$7.70 \pm 0.10$

$8.60 \pm 0.26$

$18.67 \pm 0.25$

$\begin{array}{cc}<6^{\mathrm{b}} & <6 \\ <6 & <6 \\ <6 & <6 \\ <6 & <6 \\ N D & N D \\ 11.67 \pm 0.32 & 7.93 \pm 0.35 \\ N D & N D \\ N D & N D \\ 20.92 \pm 0.72 & 20.78 \pm 1.06\end{array}$

${ }^{a}$ Results are expressed as the diameter of inhibition zone $(\mathrm{mm})$, values represent the means of three independent replicates $\pm S D$.

${ }^{b}<6$, no obvious inhibition zone was detected.

${ }^{c}$ Pure perfume lemon and its leaf essential oil with no dilution.

\#ND, not detected.

${ }^{d}$ Gatifloxacin was used as a positive control, the dosage of gatifloxacin used in the inhibition zone assay is $1 \mathrm{nmol}$.

bacterial ( $\mathrm{MIC}$ and $\mathrm{MBC}=3.2 \mathrm{mg} / \mathrm{mL}$ ), which mighty cause by some of the more volatile components, such as alcohols and aldehydes in the essential oil behaving differently in these two types of assays. Since both essential oils were derived from plant waste products, these findings indicated that recycling and reusing of these by-products can produce useful material with antibacterial activity. Moreover, it suggests that the physiochemical properties of the essential oils and their components may have further implication when apply this type of essential oils in future research and development.

\section{Killing Kinetic Studies of the Two Essential Oils}

The time killing kinetic studies were assayed over a period of $24 \mathrm{~h}$ at $37^{\circ} \mathrm{C}$ according to previous study with a slightly modification (Theophel et al., 2014; Phee et al., 2015;
Meng et al., 2016; Wu et al., 2018). Figure 4 displays the time-kill curves of the two essential oils against five bacteria strains, including three Gram-positive Staphylococcus strains (ATCC 6538, ATCC 29213, ATCC 12228), and two Gram-negative strains of Salmonella typhimurium (CMCC 50115) and Escherichia coli (CMCC 44102). As presented in Figure 4, all the bacterial strains could be effectively inhibited at the MIC of each essential oil but with a slight growth after $10 \mathrm{~h}$ ' examination, which may be because of their volatility during the assay. In addition, the bacterial growth could be effectively inhibited or killed at higher concentrations of $2 \times \mathrm{MICs}$ and $4 \times \mathrm{MICs}$, even till the end of $24 \mathrm{~h}$ assay, which is also in generally accordance with the $\mathrm{MBCs}$ results. While the bacteria strains were incubated with the $0.5 \times$ MICs of both essential oils, the bacterial concentration was initially inhibited to a certain level for 
TABLE 3 | Biological Evaluation of the two essential oils expressed in $\mathrm{MIC}^{\mathrm{a}}$ and $\mathrm{MBC}$ (b $(\mathrm{mg} / \mathrm{mL})$.

Sample code
MICs and MBCs of selected bacterium $(\mathrm{mg} / \mathrm{mL}$ or $\mathrm{ng} / \mathrm{mL})$

\begin{tabular}{|c|c|c|c|c|c|c|c|c|c|}
\hline \multicolumn{6}{|c|}{ Gram-positive bacteria strains } & \multicolumn{4}{|c|}{ Gram-negative bacteria strains } \\
\hline \multicolumn{2}{|c|}{$\begin{array}{c}\text { Staphylococcus } \\
\text { aureus (ATCC } \\
6538 \text { ) }\end{array}$} & \multicolumn{2}{|c|}{$\begin{array}{c}\text { Staphylococcus } \\
\text { aureus (ATCC } \\
\text { 29213) }\end{array}$} & \multicolumn{2}{|c|}{$\begin{array}{c}\text { Staphylococcus } \\
\text { epidermidis } \\
\text { (ATCC 12228) }\end{array}$} & \multicolumn{2}{|c|}{$\begin{array}{c}\text { Salmonella } \\
\text { typhimurium } \\
\text { (CMCC 50115) }\end{array}$} & \multicolumn{2}{|c|}{$\begin{array}{l}\text { Escherichia coli } \\
\text { (CMCC 44102) }\end{array}$} \\
\hline MIC & MBC & MIC & MBC & MIC & MBC & MIC & MBC & MIC & MBC \\
\hline 3.2 & 3.2 & 1.6 & 3.2 & 1.6 & 1.6 & 3.2 & 3.2 & 3.2 & 3.2 \\
\hline 6.4 & 6.4 & 3.2 & 3.2 & 6.4 & 6.4 & $>12.8$ & $>12.8$ & $>12.8$ & $>12.8$ \\
\hline 4 & $\mathrm{NT}^{\#}$ & 512 & NT & 256 & NT & 2 & NT & 256 & NT \\
\hline 1 & NT & 16 & NT & 4 & NT & 128 & NT & 128 & NT \\
\hline 75.08 & 75.08 & 75.08 & 75.08 & 75.08 & 75.08 & 75.08 & 75.08 & 75.08 & 75.08 \\
\hline
\end{tabular}

Perfume lemon essential oil ( $\mathrm{mg} / \mathrm{mL})$ Perfume lemon leaves essential oil $(\mathrm{mg} / \mathrm{mL})$ $(R)-(+)$-limonene $(\mathrm{mg} / \mathrm{mL})$

Citronellal $(\mathrm{mg} / \mathrm{mL})$

Gatifloxacin $^{\mathrm{c}}(\mathrm{ng} / \mathrm{mL})$

., the lowest concentration of the compound that completely inhibits the growth of bacteria.

${ }^{a} \mathrm{MICs}(\mathrm{mg} / \mathrm{mL})$, minimum inhibitory concentrations, i.e., the lowest concentration of the compound that completely inhibits the growth
${ }^{b} \mathrm{MBCs}(\mathrm{mg} / \mathrm{mL})$, minimum bacterial concentrations, i.e., the lowest concentration of the compound that completely kills the bacteria.

\#NT, not tested.

${ }^{c}$ Gatifloxacin $(\mathrm{ng} / \mathrm{mL})$ was chosen as a positive control.

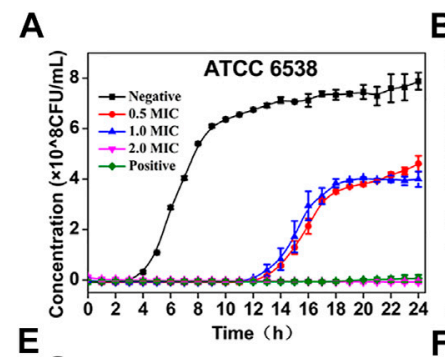

E

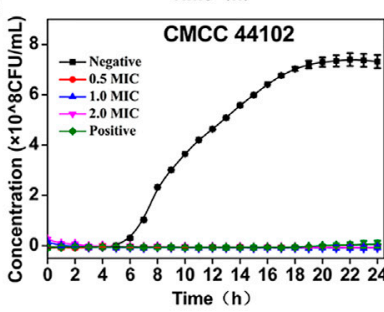

B
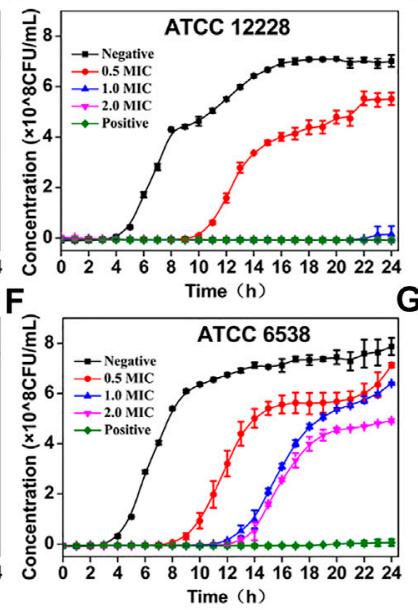

C
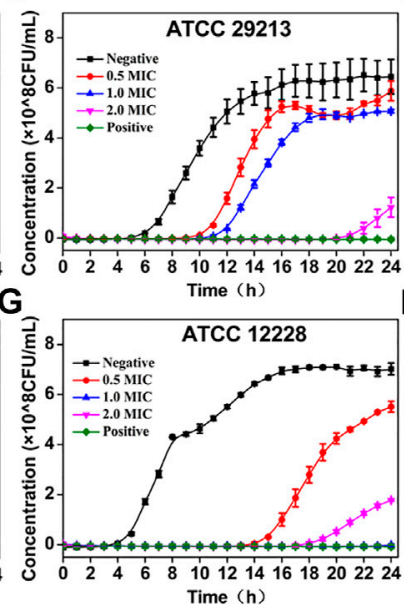

D

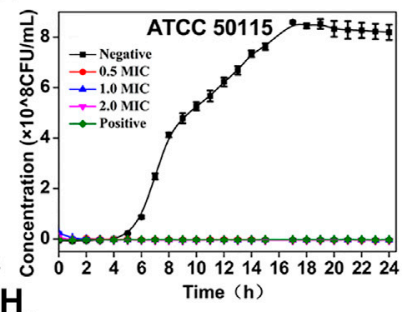

$\mathrm{H}$

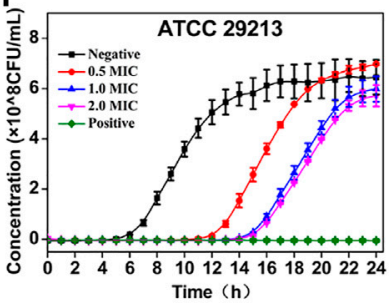

FIGURE 4 | The time killing kinetic studies of the oil extracted from discarded perfume lemon and leaves against five bacteria strains. Including Staphylococcus aureus (ATCC 6538) (A,F), Staphylococcus epidermidis (ATCC 12228) (B,G), Staphylococcus aureus subsp. Aureus (ATCC 29213) (C,H), Salmonella typhimurium (CMCC 50115) (D), Escherichia coli (CMCC 44102) (E) and exposed to four different concentrations of the oil extracted from discarded perfume lemon (Figures $\mathbf{3 A - E}$ ) and the oil extracted from discarded perfume leaves (Figures $\mathbf{3 F}-\mathbf{H}$ ) according to their respective MICs $(n=4)$, gatifloxacin was also conducted as positive control along with the two tested essential oils.

several hours then gradually increased, and no inhibitory effect was observed at the end of assay. Similar growth inhibition patterns were generally observed for the five selected bacteria strains in dose-dependent manner during the time killing kinetic studies of the two essential oils.

\section{Larvicidal Activity of the Two Essential Oils}

The larvicidal activities of the essential oils extracted from discarded perfume lemon and leaves and the two main components, $(R)-(+)$-limonene and citronellal in serial concentrations ranged from 0 to $650 \mathrm{ppm}$ were tested against fourth instar larvae of Ae. albopictus. As shown in Table 4 and Figure 5, they all showed dose-dependent manner for larvicidal potency and according to the nonlinear fitting curves of the acute toxicity study of toxicity regression equations (produced by the software of Origin 8.5), $\mathrm{LC}_{20}, \mathrm{LC}_{50}$ and $\mathrm{LC}_{80}$ values were calculated from the curve fitting equations. The larvicidal activity of the oil extracted from discarded perfume lemon was $\mathrm{LC}_{20}=$ $248.60 \mathrm{ppm}, \mathrm{LC}_{50}=384.81 \mathrm{ppm}$ and $\mathrm{LC}_{80}=595.64 \mathrm{ppm}$. The larvicidal activity of perfume lemon leaves essential oil was $\mathrm{LC}_{20}=195.73 \mathrm{ppm}, \mathrm{LC}_{50}=395.09 \mathrm{ppm}$ and $\mathrm{LC}_{80}=$ $797.52 \mathrm{ppm}$. The larvicidal activity of the $(R)$ (+)-limonene was $\mathrm{LC}_{20}=237.88 \mathrm{ppm}, \mathrm{LC}_{50}=295.28 \mathrm{ppm}$ and $\mathrm{LC}_{80}=364.26 \mathrm{ppm}$ and the activity of citronellal was $\mathrm{LC}_{20}=198.53 \mathrm{ppm}, \quad \mathrm{LC}_{50}=267.08 \mathrm{ppm}$ and $\mathrm{LC}_{80}=$ $382.92 \mathrm{ppm}$. The activity of these two main chemical components is comparable but slightly better than the corresponding essential oils, which may suggest that $(R)$ $(+)$-limonene and citronellal play a key role in the effect of essential oils on larvae. 
TABLE 4 | Acute toxicity of the two essential oils and two chemotypes against fourth instar larvae of Ae. albopictus (ppm).

Sample code

Toxicity regression equations 4th instar larvae of Ae. albopictus

\begin{tabular}{ccc}
\hline $\mathbf{L C}_{\mathbf{2 0}}(\mathbf{p p m})^{\mathbf{a}}$ & $\mathbf{L C}_{\mathbf{5 0}}(\mathbf{p p m})^{\mathbf{a}} \mathbf{( 9 5 \% \mathbf { C I } )}$ & $\mathbf{L C}_{\mathbf{8 0}}(\mathbf{p p m})^{\mathbf{a}}$ \\
248.60 & $384.81(278.464-437.534)$ & 595.64 \\
195.73 & $395.09(204.929-383.510)$ & 797.52 \\
237.88 & $295.28(255.816-328.304)$ & 364.26 \\
198.53 & $267.08(207.284-345.576)$ & 382.92 \\
0.175 & $0.531(0.055-0.148)$ & 1.615
\end{tabular}

Perfume lemon essential oil

Perfume lemon leaves essential oil

$(R)-(+)$-limonene

Citronellal

Deltamethrin $^{\mathrm{b}}$

$$
\begin{gathered}
y=118.942-120.457 /\left(1+(x / 384.808)^{3.173}\right)\left(R^{2}=0.985\right) \\
y=138.471-141.968 /\left(1+(x / 395.094)^{1.974}\right)\left(R^{2}=0.970\right) \\
y=105.266-108.298 /\left(1+(x / 297.369)^{5.864}\right)\left(R^{2}=0.975\right) \\
y=103.437-128.585 /\left(1+(x / 240.245)^{3.219}\right)\left(R^{2}=0.995\right) \\
y=118.440-153.112 /\left(1+(x / 0.531)^{1.247}\right)\left(R^{2}=0.992\right)
\end{gathered}
$$

${ }^{a} 14$ serial concentrations were selected to determine $L C_{20}, L C_{50}$ and $L C_{80}$ values. Mortality of each examined concentration was performed three replicates, five larvae each well was applied in this high throughput assay.

${ }^{b}$ Deltamethrin was treated as positive control.
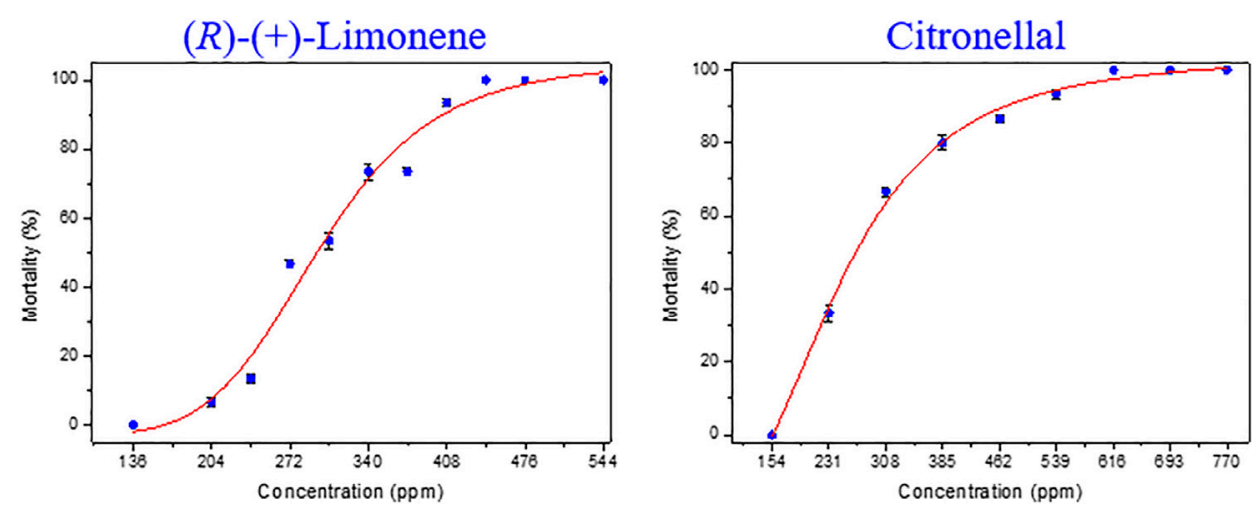

FIGURE $\mathbf{5}$ | Toxicity curve of the two chemotypes against Ae. albopictus.

TABLE 5 | Acute toxicity of the two essential oils against Ae. albopictus $\left(\mu \mathrm{g} / \mathrm{cm}^{2}\right)$.

Sample code
Toxicity regression equations
Ae. Albopictus (2-5 days)

$\begin{array}{ccc}\mathrm{LD}_{20}\left(\mu \mathrm{g} / \mathrm{cm}^{2}\right)^{\mathrm{a}} & \mathrm{LD}_{50} & \mathrm{LD}_{80}\left(\mu \mathrm{g} / \mathrm{cm}^{2}\right)^{\mathrm{a}}\end{array}$

$\begin{array}{ccc}95.180 & 133.059(106.631-142.248) & 186.014 \\ 145.071 & 218.962(140.992-202.215) & 330.489 \\ 0.0225 & 0.0659(0.027-0.059) & 0.193\end{array}$

$\begin{array}{lcccc}\text { Perfume lemon essential oil } & y=107.424-107.878 /\left(1+(x / 133.059)^{4.138}\right)\left(R^{2}=0.996\right) & 95.180 & 133.059(106.631-142.248) & 186.014 \\ \text { Perfume lemon leaves essential oil } & y=140.278-136.307 /\left(1+(x / 218.962)^{3.367}\right)\left(R^{2}=0.985\right) & 145.071 & 218.962(140.992-202.215) & 330.489 \\ \text { Deltamethrin }^{b} & y=127.489-128.998 /\left(1+(x / 0.0659)^{1.292}\right)\left(R^{2}=0.996\right) & 0.0225 & 0.0659(0.027-0.059) & 0.193\end{array}$

${ }^{a}$ At least nine serial concentrations were selected to determine $L D_{20}, L D_{50}$ and $L D_{80}$ values. Mortality of each examined concentration was performed three replicates, 10 adult female mosquitoes each concentration was applied in this assay.

${ }^{b}$ Deltamethrin was treated as positive control.

\section{Tarsal Contact Test}

A direct tarsal contact assay was performed for quantification of the anti-mosquito activity. The adulticidal bioassay of the essential oils extracted from discarded perfume lemon and leaves and the two main components $(R)-(+)$-limonene and citronellal in serial concentrations ranged from 0 to $650 \mu \mathrm{g} / \mathrm{cm}^{2}$ against 2-5 days old female adults of Ae. albopictus were performed. As shown in Table 5 and Figure 6, both essential oils revealed dose-dependent adulticidal potency and according to the nonlinear fitting curves of the acute toxicity study of toxicity regression equations (produced by the software of Origin 8.5), $\mathrm{LD}_{20}, \mathrm{LD}_{50}$ and $\mathrm{LD}_{80}$ values were calculated according to the fitting curve equations. The adulticidal activity of the essential oils extracted from discarded perfume lemon was $\mathrm{LD}_{20}=95.180 \mu \mathrm{g} / \mathrm{cm}^{2}, \mathrm{LD}_{50}=133.059 \mu \mathrm{g} / \mathrm{cm}^{2}, \mathrm{LD}_{80}$ $=186.014 \mu \mathrm{g} / \mathrm{cm}^{2}$. The adulticidal activity of perfume lemon leaves was $\mathrm{LD}_{20}=145.071 \mu \mathrm{g} / \mathrm{cm}^{2}, \mathrm{LD}_{50}=218.962 \mu \mathrm{g} / \mathrm{cm}^{2}$ and $\mathrm{LD}_{80}=330.489 \mu \mathrm{g} / \mathrm{cm}^{2}$, which were less active than the essential oil extracted from the fruit. Surprisingly, the two components with good activity against larvae when tested alone failed to produce promising activity against any of the mosquito larvae (mortality $>50 \%$ was observed only at the higher test dosage). In the present study, GC-MS data (Table 1) reveals that besides $(R)-(+)$-limonene and citronellal there are many other terpenoids and related compounds present in the oil. Thus, the activity of the two essential oils against the adult mosquito $\left(\mathrm{LD}_{50}=133.059-218.962 \mu \mathrm{g} / \mathrm{cm}^{2}\right)$ may be attributed to the additive or synergistic or blend effect of many/some of the 

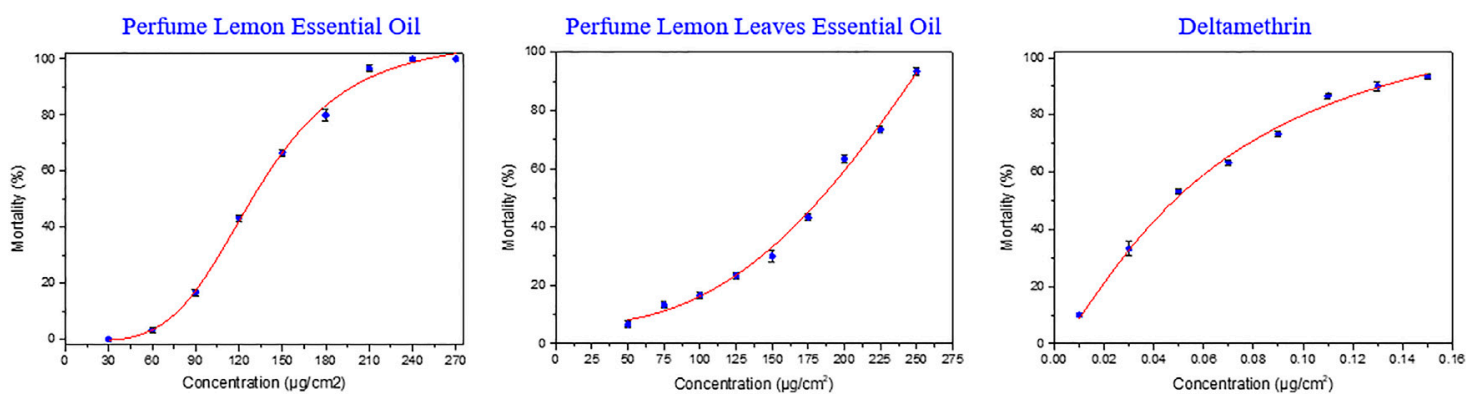

FIGURE 6 | Toxicity curve of the two essential oils against Ae. albopictus.

constituents. This effect has previously been observed in some other essential oils, whose activity is due to the combination of the main components, but no significant activity has been found with single components alone (Papachristos et al., 2004). Overall, these two essential oils have certain insecticidal activity against adult mosquitoes.

\section{CONCLUSION}

In summary, discarded perfume lemon and leaves, which were often disposed as waste by-produces, were recycled and reused during this study. The two essential oils were produced by traditional hydro-distillation with good yields. Kovats indices method was applied to identify the constituents and their relative content in the essential oils by GC-MS. 26 chemical components were identified, representing almost $100 \%$ of the total amount. The bioassay results implied that both essential oils present antibacterial activity, especially for the Gram-positive Staphylococcus bacterial strains. Moreover, the antimosquito potential of the two essential oils was also clearly demonstrated in their larvicidal and adulticidal activities. Therefore, the development of the essential oils extracted from discarded perfume lemon and leaves is not only friendly to the environment and ecology, but also can provide added value to the agricultural process.

As far as the comparison between $(R)-(+)$-Limonene and Citronellal is concerned, the insecticidal activity of the oxygenated monoterpenoids is higher than that of containing hydrocarbons. This conclusion is consistent with the previous findings (Regnault-Roger et al., 1993; Papachristos et al., 2004). However, these two chemicals showed significantly lower adulticidal activity than that of essential oils in this study. This finding suggests the insecticidal activity of the researched essential oil is not directly related to the content of its main components. In addition, the mode of action of these two essential oils from this study and from other similar studies remains to be elucidated (Sheng et al., 2020). This is one of the significant barriers for the further development of plant origin essential oils whilst chemical standardization and quality control are other challenge in the development process. The study of molecular mechanisms of the active components may potentially guide the development of more efficient new vector control or antibacterial agents. Relevant research is undergoing and the results will be reported in due course.

\section{Statistical Analysis}

The results are expressed as the mean \pm standard deviation (SD).

\section{DATA AVAILABILITY STATEMENT}

The original contributions presented in the study are included in the article/Supplementary Material, further inquiries can be directed to the corresponding authors.

\section{AUTHOR CONTRIBUTIONS}

PW: Conceptualization, Methodology, Software, XT: Writing- Reviewing and Editing, Software, RJ: WritingOriginal draft preparation, JL: Data curation, ML: Data curation, HD: Validation, KW: Writing- Original draft preparation, ZS: Original draft preparation; BC: Conceptualization, XX: Software, Validation, CL: Data curation, ZL: Conceptualization, QZ: Data curation, XZ: Writing- Reviewing and Editing, KZ: Writing- Reviewing and Editing, DL: Supervision, Writing- Reviewing and Editing, WH: Supervision, Writing- Reviewing and Editing.

\section{FUNDING}

This study was supported by National Natural Science Foundation of China (No. 81803390), Guangdong Basic and Applied Basic Research Foundation (No. 2021A1515010221), Special Fund Project of Science and Technology Innovation Strategy of Guangdong Province 2018 and 2020 (No. Jiangke (2018)352 and Jiangke (2020)182), the project of Jiangmen city social welfare innovation platform construction (No. 2016350100170008351, 2018090103460022105). The authors are also grateful to the foundation of Department of 
Education of Guangdong Province (No. 2020KZDZX1202, 2018KTSCX236, 2017KSYS010 and 2016KCXTD005) and Jiangmen Program for Innovative Research Team (No. 2018630100180019806) and the Youth Foundation of Wuyi University (No. 2017td01).

\section{REFERENCES}

Bakkali, F., Averbeck, S., Averbeck, D., and Idaomar, M. (2008). Biological Effects of Essential Oils - A Review. Food Chem. Toxicol. 46, 446-475. doi:10.1016/j.fct. 2007.09.106

Benamrouche, N., Lazri, M., Tali-Maamar, H., and Rahal, K. (2014). Comparaison de la Sensibilité aux Antibiotiques de Corynebacterium Diphtheriae par les Mméthodes de Dilution en Bouillon et de Diffusion (E-test et Disques). Méd. Mal. Infect. 44, 392-393. doi:10.1016/j.medmal.2014.07.007

Bhatt, S., Gething, P. W., Brady, O. J., Messina, J. P., Farlow, A. W., Moyes, C. L., et al. (2013). The Global Distribution and burden of Dengue. Nature 496, 504-507. doi:10.1038/nature12060

Chang, K.-S., Kim, H.-C., Klein, T. A., and Ju, Y. R. (2017). Insecticide Resistance and Cytochrome-P450 Activation in Unfed and Blood-Fed Laboratory and Field Populations of Culex pipiens Pallens. J. Pest Sci. 90, 759-771. doi:10.1007/ s10340-016-0820-1

Chansang, A., Champakaew, D., Junkum, A., Jitpakdi, A., Amornlerdpison, D., Aldred, A. K., et al. (2018). Synergy in the Adulticidal Efficacy of Essential Oils for the Improvement of Permethrin Toxicity against Aedes aegypti L. (Diptera: Culicidae). Parasites \& Vectors 11, 417. doi:10.1186/ s13071-018-3001-7

Chouaïb, K., Hichri, F., Nguir, A., Daami-Remadi, M., Elie, N., Touboul, D., et al. (2015). Semi-synthesis of New Antimicrobial Esters from the Natural Oleanolic and Maslinic Acids. Food Chem. 183, 8-17. doi:10.1016/j.foodchem.2015. 03.018

Ciriminna, R., Fidalgo, A. M., Carnaroglio, D., Tamburino, A., Cravotto, G., Ilharco, L. M., et al. (2017). Lemon Essential Oil of Variable Composition by Changing the Conditions of the Extraction from Lemon Peel via Microwave Hydrodiffusion and Gravity. ChemistrySelect 2, 7123-7127. doi:10.1002/slct. 201701471

Derua, Y. A., Kweka, E. J., Kisinza, W. N., Githeko, A. K., and Mosha, F. W. (2019). Bacterial Larvicides Used for Malaria Vector Control in Sub-saharan Africa: Review of Their Effectiveness and Operational Feasibility. Parasites Vectors 12, 426. doi:10.1186/s13071-019-3683-5

dos Santos Moreira, A. M., Bittencourt, V. C. E., Costa, F. L. S., Elena de Lima, M., Lopes, M. T. P., Borges, W. S., et al. (2018). Hydrophobic Nanoprecipitates of $\beta$-Cyclodextrin/Avermectins Inclusion Compounds Reveal Insecticide Activity against Aedes aegypti Larvae and Low Toxicity against Fibroblasts. J. Agric. Food Chem. 66, 7275-7285. doi:10.1021/acs.jafc.8b01300

Duguma, D., Rueda, L. M., and Debboun, M. (2020). "Chapter 11 - MosquitoBorne Diseases," in Mosquitoes, Communities, and Public Health in Texas, Editors M. Debboun, M. R. Nava, and L. M. Rueda (Cambridge, MA: Academic Press), 319-337. doi:10.1016/b978-0-12-814545-6.00011-0

Gaudreau, C., Girouard, Y., Gilbert, H., Gagnon, J., and Bekal, S. (2008). Comparison of Disk Diffusion and Agar Dilution Methods for Erythromycin, Ciprofloxacin, and Tetracycline Susceptibility Testing of Campylobacter Coli and for Tetracycline Susceptibility Testing of Campylobacter Jejuni Subsp. Jejuni. Aac 52, 4475-4477. doi:10.1128/aac.00767-08

Gross, A. D., Norris, E. J., Kimber, M. J., Bartholomay, L. C., and Coats, J. R. (2017). Essential Oils Enhance the Toxicity of Permethrin againstAedes aegyptiandAnopheles Gambiae. Med. Vet. Entomol. 31, 55-62. doi:10.1111/ mve. 12197

Ivory, M. O., Birchall, J. C., and Piguet, V. (2015). Early Dengue Virus Infection in Human Skin: A Cycle of Inflammation and Infectivity. J. Invest. Dermatol. 135, 1711-1712. doi:10.1038/jid.2014.544

Jabrane, A., Ben Jannet, H., Mastouri, M., Mighri, Z., and Casanova, J. (2010). Chemical Composition and In Vitro Evaluation of Antioxidant and

\section{ACKNOWLEDGMENTS}

Sincere and heartfelt thanks must go to Mrs. Sulian Liang who has given generous suggestions on the English language of the manuscript.

Antibacterial Activities of the Root Oil of Ridolfia Segetum (L.) Moris from Tunisia. Nat. Product. Res. 24, 491-499. doi:10.1080/14786410802228520

Lees, R., Praulins, G., Davies, R., Brown, F., Parsons, G., White, A., et al. (2019). A Testing cascade to Identify Repurposed Insecticides for Next-Generation Vector Control Tools: Screening a Panel of Chemistries with Novel Modes of Action against a Malaria Vector. Gates Open Res. 3, 1464. doi:10.12688/ gatesopenres.12957.2

Liu, N. (2015). Insecticide Resistance in Mosquitoes: Impact, Mechanisms, and Research Directions. Annu. Rev. Entomol. 60, 537-559. doi:10.1146/annurevento-010814-020828

Luangtongkum, T., Morishita, T. Y., El-Tayeb, A. B., Ison, A. J., and Zhang, Q. (2007). Comparison of Antimicrobial Susceptibility Testing of Campylobacter Spp. By the agar Dilution and the agar Disk Diffusion Methods. J. Clin. Microbiol. 45, 590-594. doi:10.1128/jcm.00986-06

Meng, Y., Hou, X., Lei, J., Chen, M., Cong, S., Zhang, Y., et al. (2016). Multifunctional Liposomes Enhancing Target and Antibacterial Immunity for Antimicrobial and Anti-biofilm against Methicillin-Resistant Staphylococcus aureus. Pharm. Res. 33, 763-775. doi:10.1007/s11095-015-1825-9

Papachristos, D. P., Karamanoli, K. I., Stamopoulos, D. C., and MenkissogluSpiroudi, U. (2004). The Relationship between the Chemical Composition of Three Essential Oils and Their Insecticidal Activity againstAcanthoscelides obtectus(Say). Pest Manag. Sci. 60, 514-520. doi:10.1002/ps.798

Pavela, R., and Benelli, G. (2016). Essential Oils as Ecofriendly Biopesticides? Challenges and Constraints. Trends Plant Sci. 21, 1000-1007. doi:10.1016/j. tplants.2016.10.005

Pavela, R. (2015). Essential Oils for the Development of Eco-Friendly Mosquito Larvicides: A Review. Ind. Crops Prod. 76, 174-187. doi:10.1016/j.indcrop.2015. 06.050

Peng, C., Zhao, S.-Q., Zhang, J., Huang, G.-Y., Chen, L.-Y., and Zhao, F.-Y. (2014). Chemical Composition, Antimicrobial Property and Microencapsulation of Mustard (Sinapis alba) Seed Essential Oil by Complex Coacervation. Food Chem. 165, 560-568. doi:10.1016/j.foodchem.2014.05.126

Phee, L. M., Betts, J. W., Bharathan, B., and Wareham, D. W. (2015). Colistin and Fusidic Acid, a Novel Potent Synergistic Combination for Treatment of Multidrug-Resistant Acinetobacter Baumannii Infections. Antimicrob. Agents Chemother. 59, 4544-4550. doi:10.1128/aac.00753-15

Ranson, H., and Lissenden, N. (2016). Insecticide Resistance in African Anopheles Mosquitoes: A Worsening Situation that Needs Urgent Action to Maintain Malaria Control. Trends Parasitol. 32, 187-196. doi:10.1016/j.pt. 2015.11.010

Regnault-Roger, C., Hamraoui, A., Holeman, M., Theron, E., and Pinel, R. (1993). Insecticidal Effect of Essential Oils from Mediterranean Plants uponAcanthoscelides Obtectus Say (Coleoptera, Bruchidae), a Pest of Kidney Bean (Phaseolus vulgaris L.). J. Chem. Ecol. 19, 1233-1244. doi:10. 1007/bf00987383

Rouis, Z., Laamari, A., Abid, N., Elaissi, A., Cioni, P. L., Flamini, G., et al. (2013). Chemical Composition and Larvicidal Activity of Several Essential Oils from Hypericum Species from Tunisia. Parasitol. Res. 112, 699-705. doi:10.1007/ s00436-012-3189-y

Sader, H. S., Fritsche, T. R., and Jones, R. N. (2006). Daptomycin Bactericidal Activity and Correlation between Disk and Broth Microdilution Method Results in Testing of Staphylococcus aureus Strains with Decreased Susceptibility to Vancomycin. Aac 50, 2330-2336. doi:10.1128/aac.01491-05

Seo, S.-M., Jung, C.-S., Kang, J., Lee, H.-R., Kim, S.-W., Hyun, J., et al. (2015). Larvicidal and Acetylcholinesterase Inhibitory Activities of Apiaceae Plant Essential Oils and Their Constituents againstAedes Albopictusand Formulation Development. J. Agric. Food Chem. 63, 9977-9986. doi:10. 1021/acs.jafc.5b03586 
Shaw, W. R., and Catteruccia, F. (2019). Vector Biology Meets Disease Control: Using Basic Research to Fight Vector-Borne Diseases. Nat. Microbiol. 4, 20-34. doi:10.1038/s41564-018-0214-7

Sheng, Z., Jian, R., Xie, F., Chen, B., Zhang, K., Li, D., et al. (2020). Screening of Larvicidal Activity of 53 Essential Oils and Their Synergistic Effect for the Improvement of Deltamethrin Efficacy against Aedes albopictus. Ind. Crops Prod. 145, 112131. doi:10.1016/j.indcrop.2020.112131

Theophel, K., Schacht, V. J., Schluter, M., Schnell, S., Stingu, C. S., Schaumann, R., et al. (2014). The Importance of Growth Kinetic Analysis in Determining Bacterial Susceptibility against Antibiotics and Silver Nanoparticles. Front. Microbiol. 5, 544. doi:10.3389/fmicb.2014.00544

Weill, M., Lutfalla, G., Mogensen, K., Chandre, F., Berthomieu, A., Berticat, C., et al. (2003). Insecticide Resistance in Mosquito Vectors. Nature 423, 136-137. doi:10.1038/423136b

WHO (2005). Guidelines for Laboratory and Field Testing of Mosquito Larvicides. Geneva, Switzerland: World Health Organization. WHO/CDS/WHOPES/ GCDPP/2005.13

Wilson, A. L., Courtenay, O., Kelly-Hope, L. A., Scott, T. W., Takken, W., Torr, S. J., et al. (2020). The Importance of Vector Control for the Control and Elimination of Vector-Borne Diseases. Plos Negl. Trop. Dis. 14, e0007831. doi:10.1371/ journal.pntd.0007831

Wu, P.-P., He, H., Hong, W. D., Wu, T.-R., Huang, G.-Y., Zhong, Y.-Y., et al. (2018). The Biological Evaluation of Fusidic Acid and its Hydrogenation Derivative as Antimicrobial and Anti-inflammatory Agents. Infect. Drug Resist. 11, 1945-1957. doi:10.2147/idr.s176390
Wu, P., Tu, B., Liang, J., Guo, S., Cao, N., Chen, S., et al. (2021). Synthesis and Biological Evaluation of Pentacyclic Triterpenoid Derivatives as Potential Novel Antibacterial Agents. Bioorg. Chem. 109, 104692. doi:10.1016/j.bioorg.2021.104692

Yazgan, H., Ozogul, Y., and Kuley, E. (2019). Antimicrobial Influence of Nanoemulsified Lemon Essential Oil and Pure Lemon Essential Oil on Food-Borne Pathogens and Fish Spoilage Bacteria. Int. J. Food Microbiol. 306, 108266. doi:10.1016/j.ijfoodmicro.2019.108266

Zhang, H., Xie, Y., Liu, C., Chen, S., Hu, S., Xie, Z., et al. (2017). Comprehensive Comparative Analysis of Volatile Compounds in Citrus Fruits of Different Species. Food Chem. 230, 316-326. doi:10.1016/j.foodchem.2017.03.040

Conflict of Interest: BC was employed by the company Guangdong Xinbaotang Biotechnology Co. Ltd.

The remaining authors declare that the research was conducted in the absence of any commercial or financial relationships that could be construed as a potential conflict of interest.

Copyright (c) 2021 Wu, Tang, Jian, Li, Lin, Dai, Wang, Sheng, Chen, Xu, Li, Lin, Zhang, Zheng, Zhang, Li and Hong. This is an open-access article distributed under the terms of the Creative Commons Attribution License (CC BY). The use, distribution or reproduction in other forums is permitted, provided the original author(s) and the copyright owner(s) are credited and that the original publication in this journal is cited, in accordance with accepted academic practice. No use, distribution or reproduction is permitted which does not comply with these terms. 